\title{
Chimeric HP-PRRSV2 containing an ORF2-6 consensus sequence induces antibodies with broadly neutralizing activity and confers cross protection against virulent NADC30-like isolate
}

Nanhua Chen ${ }^{1,2,3,4^{*}} \mathbb{D}$, Shubin $\mathrm{Li}^{1}$, Yunfei Tian ${ }^{1}$, Xinshuai $\mathrm{Li}^{1}$, Shuai $\mathrm{Li}^{1}$, Jixiang $\mathrm{Li}^{1}$, Ming Qiu ${ }^{1}$, Zhe Sun ${ }^{5}$,

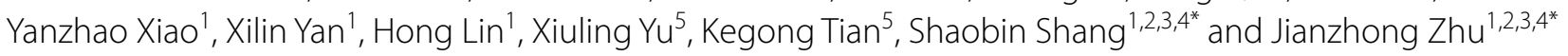

\begin{abstract}
Due to the substantial genetic diversity of porcine reproductive and respiratory syndrome virus (PRRSV), commercial PRRS vaccines fail to provide sufficient cross protection. Previous studies have confirmed the existence of PRRSV broadly neutralizing antibodies (bnAbs). However, bnAbs are rarely induced by either natural infection or vaccination. In this study, we designed and synthesized a consensus sequence of PRRSV2 ORF2-6 genes (ORF2-6-CON) encoding all envelope proteins based on 30 representative Chinese PRRSV isolates. The ORF2-6-CON sequence shared $>90 \%$ nucleotide identities to all four lineages of PRRSV2 isolates in China. A chimeric virus (rJS-ORF2-6-CON) containing the ORF2-6-CON was generated using the avirulent HP-PRRSV2 JSTZ1712-12 infectious clone as a backbone. The rJS-ORF2-6-CON has similar replication efficiency as the backbone virus in vitro. Furthermore, pig inoculation and challenge studies showed that rJS-ORF2-6-CON is not pathogenic to piglets and confers better cross protection against the virulent NADC30-like isolate than a commercial HP-PRRS modified live virus (MLV) vaccine. Noticeably, the rJS-ORF2-6-CON strain could induce bnAbs while the MLV strain only induced homologous nAbs. In addition, the lineages of VDJ repertoires potentially associated with distinct nAbs were also characterized. Overall, our results demonstrate that rJS-ORF2-6-CON is a promising candidate for the development of a PRRS genetic engineered vaccine conferring cross protection.
\end{abstract}

Keywords: PRRSV, Infectious clone, ORF2-6 consensus sequence, Broadly neutralizing antibodies, Cross protection, Genetic engineered vaccine

*Correspondence: chnhlh@126.com; shaobinshang@yzu.edu.cn; jzzhu@yzu.edu.cn

${ }^{1}$ College of Veterinary Medicine, Yangzhou University, Yangzhou 225009, Jiangsu, China

Full list of author information is available at the end of the article

\section{Introduction}

Porcine reproductive and respiratory syndrome (PRRS) is an economically significant viral disease in the swineproducing countries of the world. The clinical symptoms are characterized by reproductive failure in sows and respiratory disease in young pigs [1]. The causative agent, PRRS virus (PRRSV), is one of the most rapidly evolving RNA viruses [2]. PRRSV can be divided into two species: PRRSV1 and PRRSV2, which share $~ 60 \%$

c) The Author(s) 2021. This article is licensed under a Creative Commons Attribution 4.0 International License, which permits use, sharing, adaptation, distribution and reproduction in any medium or format, as long as you give appropriate credit to the original author(s) and the source, provide a link to the Creative Commons licence, and indicate if changes were made. The images or other third party material in this article are included in the article's Creative Commons licence, unless indicated otherwise in a credit line to the material. If material is not included in the article's Creative Commons licence and your intended use is not permitted by statutory regulation or exceeds the permitted use, you will need to obtain permission directly from the copyright holder. To view a copy of this licence, visit http://creativeco mmons.org/licenses/by/4.0/. The Creative Commons Public Domain Dedication waiver (http://creativecommons.org/publicdomain/ zero/1.0/) applies to the data made available in this article, unless otherwise stated in a credit line to the data. 
genomic similarity [3]. Furthermore, PRRSV1 has been classified into three subtypes, while PRRSV2 contains nine different lineages with genetic distances $>10 \%$ [4].

In China, even though PRRSV1 isolates were sporadically detected in recent years, PRRSV2 isolates were obviously predominant [5]. In 1995, PRRSV2 was first identified in Chinese swine herds [6]. In 2006, highly pathogenic PRRSV2 (HP-PRRSV2) variants first emerged in China, which were characterized by high fever $\left(40-42{ }^{\circ} \mathrm{C}\right)$, high morbidity $(50-100 \%)$ and high mortality (20-100\%) in all ages of pigs [7]. Since 2013, NADC30-like PRRSV2 variants have become prevalent in China [8]. Since 2017, NADC34-like PRRSV2 isolates have also been detected [9]. To make matters worse, the coexistence of distinct PRRSV isolates within one pig herd or even within one pig has been identified in the field $[5,10]$.

Several commercial PRRS modified live virus (MLV) vaccines have been widely utilized in China, including RespPRRS MLV, CH-1R, R98, JXA1-R, HuN4-F112, TJM-F92 and GDr180. Generally, immunization with commercial PRRS MLV vaccines confers excellent homologous protection against closely related isolates but only limited cross protection against heterologous strains [11]. Due to the extraordinary ability of PRRSV to mutate and generate substantial genetic variations, the development of a broadly protective PRRS vaccine is particularly important to combat the continuously emerging PRRS outbreaks.

Neutralizing antibodies (nAbs) are a vital component of the immune armory against viral infection, which are induced against the viral outer coat proteins or envelope proteins [12]. The PRRSV virion surface contains at least seven envelope proteins. Open reading frames (ORF) 5 and 6 encode the major envelope proteins, GP5 and M, which form a disulfide-linked heterodimer. ORF 2, 3 and 4 encode the minor glycoproteins GP2a, GP3 and GP4 that form a noncovalent heterotrimer. Two small nonglycosylated proteins, E and $5 \mathrm{a}$, are encoded by ORF2b and ORF5a, respectively [13]. Several studies have identified multiple neutralizing epitopes distributing among the major structural proteins (GP5 and $\mathrm{M}$ ) and minor glycoproteins (GP2a, GP3 and GP4) [13-15]. In addition, the recognition of different neutralizing epitopes may induce homologous nAbs, heterologous nAbs or even broad nAbs (bnAbs) [13, 16, 17]. Similar results have been described in viruses such as human immunodeficiency virus (HIV) and influenza virus $[18,19]$. PRRSV bnAbs have been found in sera from both naturally or experimentally infected pigs $[12,13]$. However, PRRSV infection or vaccination generally induces delayed and ineffectual production of nAbs [12]. Specifically, bnAbs are only induced in about $1 \%$ of PRRSV infected pigs [17].
Multiple strategies have been employed to increase the breadth, potency and longevity of nAbs against rapidly evolving viruses, including epitope masking, sequential vaccination and centralized envelope antigens [19]. To overcome the extraordinary genetic diversity of PRRSV, several chimeric viruses were generated by molecular breeding of individual envelope protein (GP3, GP4, GP5, or M) from genetically divergent isolates, which could elicit heterologous cross-neutralizing antibodies [20-22]. However, the heterologous protection of these chimeric viruses in pigs was not assessed. A chimeric PRRSV containing multiple shuffled envelope genes could induce heterologous nAbs and confer partial cross protection against heterologous challenge [23]. According to the approach of centralized sequences [19], a PRRSV2 consensus full genome was designed and synthesized, which could confer broad levels of heterologous protection but the synthetic virus is highly virulent [11].

Here we hypothesized that a chimeric virus containing the consensus sequence encoding envelope proteins of PRRSV may induce broader nAbs. Therefore, a consensus sequence of ORF2-6 genes (ORF2-6-CON) encoding all envelope proteins of PRRSV was designed and synthesized. An infectious clone of avirulent HPPRRSV2 isolate JSTZ1712-12 was first generated (named as rJSTZ1712-12) as we previously described [24, 25], and then used as the backbone for the construction of a chimeric virus containing ORF2-6-CON (designated as rJS-ORF2-6-CON). The chimeric virus is fully infectious in vitro and in vivo. More importantly, pig inoculation and challenge studies show that the rJS-ORF2-6-CON strain is avirulent, may induce bnAbs and confers satisfied cross protection against a virulent NADC30-like PRRSV isolate.

\section{Materials and methods PRRSV strains and cells}

PRRSV strains used in this study were all stored in our laboratories including the following: PRRSV1: HLJB1 strain [26]; JXA1-like HP-PRRSV2: JSTZ1712-12 and JXA1-R strains [24]; CH-1a-like PRRSV2: SD1612-1 and CH-1R strains [27]; VR-2332-like PRRSV2: JSYC20-05-1 and R98 strains [27]; NADC30-like PRRSV2: SD17-36 and SD17-38 strains [28, 29]; NADC34-like PRRSV2: Anheal-1 strain (GenBank accession no. MH370474) was a courtesy from Dr Xizhao Chen at Beijing Anheal Laboratories Co. Ltd. Monkey kidney Marc-145 cells and baby hamster kidney 21 (BHK-21) cells were cultured in Dulbecco minimum essential median (DMEM) supplemented with $10 \%$ fetal bovine serum (FBS) and antibiotics. Pulmonary alveolar macrophages (PAM) were harvested by lung lavage from 6-week-old PRRSV-negative pigs [30]. PAM were maintained in Roswell Park 
Memorial Institute 1640 medium (RPMI-1640) supplement with $10 \%$ FBS and antibiotics.

\section{Design and synthesis of a PRRSV2 ORF2- 6 consensus sequence}

The approach so called "centralized envelope antigens" was adopted to overcome the extraordinary genetic diversity of PRRSV isolates [19]. To design a consensus sequence that contains the most common amino acids at each position of the envelope proteins, we collected 30 representative Chinese PRRSV isolates from GenBank. The ORF2-6 gene sequences encoding envelope proteins were aligned using ClustalX 2.0 [31]. The consensus ORF2-6 sequence (ORF2-6-CON) was generated using the DNAMAN 6.0 program. The ORF2-6-CON sequence was compared with the corresponding region in the JSTZ1712-12 strain (MK906026), frameshift mutations were manually revised to ensure the proper expression of all envelope proteins [11]. The ORF2-6-CON sequence was synthesized by the GENEWIZ Company (Suzhou, China).

\section{Construction and rescue of a chimeric HP-PRRSV2 with ORF2-6-CON}

To generate an infectious clone carrying the ORF26-CON sequence, a full-genome cDNA clone of the avirulent HP-PRRSV2 isolate, JSTZ1712-12, was first constructed as we previously described [25]. Three overlapped fragments (F1, F2 and F3) spanning the full-length genome of JSTZ1712-12 were produced by PCR amplification using high fidelity PrimeSTAR MAX DNA Polymerase (TaKaRa, Shiga, Japan) with a panel of primers (Table 1). In the F3 fragment, a copy of the hepatitis D virus (HDV) ribozyme sequence was added immediately following the poly (A) tail via two rounds of PCR amplifications using JSTZ1712-12-AscI-F3/JSTZ1712-12-1R3 and JSTZ1712-12-AscI-F3/JSTZ1712-12-NotI-2R3 primer pairs. Four restriction enzyme sites (PacI, AflII, AscI and NotI) were used for assembling of the fulllength JSTZ1712-12 clone (rJSTZ1712-12).

To construct the chimeric virus containing ORF2-6$\mathrm{CON}$, overlap extension PCR was performed to generate a recombined F3 fragment carrying the ORF2-6-CON. In details, the synthetic ORF2-6-CON sequence (in pUC57 vector) was amplified with the PRRSV2-AscIORF2-CON-F3/PRRSV2-ORF6-CON-R primer pairs to produce a fragment PRRSV2-AscI-ORF2-6-CON. In addition, the rJSTZ1712-12 clone was amplified with the PRRSV2-ORF6-CON-F2/JSTZ1712-12-NotI-2R3 primers to generate the JSTZ1712-12-ORF6-3UTRNotI fragment. Then an overlap PCR was performed with PRRSV2-AscI-ORF2-CON-F3/JSTZ1712-12-NotI2R3 primers using the PRRSV2-AscI-ORF2-6-CON and JSTZ1712-12-ORF6-3UTR-NotI fragments as templates to generate chimeric F3 containing ORF2-6-CON (ORF2-6-CON-F3). The recombined ORF2-6-CON-F3 was double-digested with AscI and NotI and then ligated into the rJSTZ1712-12 clone, which was linearized with the same restriction enzymes to generate the rJSTZ171212-ORF2-6-CON clone (abbreviated as rJS-ORF2-6CON). The rJS-ORF2-6-CON genome sequence has been submitted to GenBank (MW460545).

The rJSTZ1712-12 and rJS-ORF2-6-CON clones obtained were transfected into BHK-21 cells using Lipofectamine 3000 Reagent (Invitrogen, USA) according to the manufacturer's instructions. The culture supernatants collected at $48 \mathrm{~h}$ post-transfection (hpt) were serially passaged in Marc-145 cells. The recovery of the

Table 1 PCR primers used for the construction of PRRSV infectious clones.

\begin{tabular}{|c|c|c|c|}
\hline No & Primer & Sequence $\left(5^{\prime}-3\right)^{a}$ & Length (bp) \\
\hline 1 & JSTZ1712-12-Pacl-F1 & AGCTCGITAATTAATACATGACGTATAGGTGTTGGCT & 37 \\
\hline 2 & JSTZ1712-12-AflII-R1 & CATAGGTGCTTAAGTTCATTACCACCTGTAACGGAT & 36 \\
\hline 3 & JSTZ1712-12-AfllI-F2 & ATCCGTTACAGGTGGTAATGAACTTAAGCACCTATG & 36 \\
\hline 4 & JSTZ1712-12-Ascl-R2 & CCTTTCTGGCGCGCCCGAAAC & 21 \\
\hline 5 & JSTZ1712-12-Ascl-F3 & GTTTCGGGCGCGCCAGAAAGG & 21 \\
\hline 6 & JSTZ1712-12-1R3 & AGCGAGGAGGCTGGGACCATGCCGGCCTTTTTTTTTTTTTTTTTTTTTAATTACGGCCGCATGGTTCT & 68 \\
\hline 7 & JSTZ1712-12-Notl-2R3 & $\begin{array}{l}\text { ACAGGCGGCCGCGTCCCATTCGCCATTACCGAGGGGACGGTCCCCTCGGAATGTTGCCCAGCCGGCGCCAGC } \\
\text { GAGGAGGCTGGGACCAT }\end{array}$ & 89 \\
\hline 8 & PRRSV2-Ascl-ORF2-CON-F3 & $\begin{array}{l}\text { TTTCGGGCGCGCCAGAAAGGGAAAATTTATAAAGCTAATGCCACCAGCATGAGGTTTCATTTTCCCCCGG } \\
\text { GCCCT }\end{array}$ & 75 \\
\hline 9 & PRRSV2-ORF6-CON-R & TTCTTTTTCTTTTGCTGCTTGCCGTTGTTATTTGGCATATTTGACAAGGTTTACCACTCCCTGT & 64 \\
\hline 10 & PRRSV2-ORF6-CON-F2 & ACAGGGAGTGGTAAACCTTGTCAAATATGCCAAATAACAACGGCAAGCAGCAAAAGAAAAAGAA & 64 \\
\hline
\end{tabular}

${ }^{a}$ The unique restriction enzyme sites used for cloning purposes are underlined.

${ }^{b}$ The hepatitis D virus ribozyme sequence is shown in italic and the overlapped region is highlighted in bold. 
infectious viruses was confirmed by indirect immunofluorescence assay (IFA) [24]. PRRSV-specific murine mAb 15A1 (1:500 dilution) against the $\mathrm{N}$ protein was used as the primary antibody, while the Dylight 594 (Goat antimouse IgG, 1:1000, Invitrogen) was used as the secondary antibody. To study the growth kinetics of the viruses in vitro, Marc-145 cells were infected with 200 median tissue culture infectious doses $\left(\mathrm{TCID}_{50}\right)$ of rJS-ORF2-6CON, rJSTZ1712-12 or parental JSTZ1712-12 isolate, respectively. The multiple-step growth curves within 96 $\mathrm{h}$ post-infection (hpi) were determined by real-time RTPCR assay [32]. The plaque morphology was examined in Marc-145 cells as previously described [33].

\section{Animal inoculation and challenge study}

To evaluate the safety and immunogenicity of rJS-ORF26-CON, pig inoculation and challenge studies were performed. All animal experiments in this study were approved by the Animal Welfare and Ethics Committee of Yangzhou University with the Reference number of 202010001. Twenty 4-week-old PRRSV-free piglets were randomly divided into four groups (five piglets in each group). Piglets in the first group were intranasally and intramuscularly inoculated with $2 \mathrm{~mL} 10^{5.0} \mathrm{TCID}_{50} /$ $\mathrm{mL}$ rJS-ORF2-6-CON (5th passage). Piglets in the second group were injected with one dose of the commercial TJM-F92 vaccine (TECON, Xinjiang, China). Piglets in the other two groups were inoculated with RPMI-1640 to serve as the control. At 42 days post-inoculation (dpi), in addition to one RPMI-1640 inoculated group that was mock-infected again, the other three groups of pigs were challenged with $2 \mathrm{~mL} 10^{5.0} \mathrm{TCID}_{50} / \mathrm{mL}$ of the virulent NADC30-like SD17-38 isolate [29].

Rectal temperature was recorded daily during the first 2 weeks both after inoculation and after challenge. The body weight was measured weekly and clinical signs were assessed daily. Serum samples were collected weekly for the analyses of virus load, antibody and IFN- $\gamma$ levels. The dynamics of viremia were analyzed by PRRSV realtime RT-PCR assay [32]. PRRSV-specific antibodies in the sera were detected by HerdCheck ${ }^{\circledR}$ PRRS $\times 3$ ELISA Kit (IDEXX, ME, USA). The threshold for seroconversion was set at a sample-to-positive $(\mathrm{s} / \mathrm{p})$ ratio of 0.4 . In addition, IFN- $\gamma$ in the sera were detected using the commercial Porcine IFN-gamma ELISA kit (ABSIN, Beijing, China) according to the manufacturer's instructions. The weekly collected sera since 28 dpi were submitted to virus neutralization test as we previously described $[13,17]$. The absence of a cytopathic effect (CPE) at a 1:8 dilution was considered positive for the presence of virus neutralizing activity. The pigs that survived until 14 days post-challenge (dpc) were euthanized and tissue samples including lungs, tonsils and lymph nodes were collected for histopathological and immunohistochemical examinations [7].

\section{Flow cytometric analysis of PRRSV-specific IFN- $\gamma$ secreting cells}

Swine periphery blood mononuclear cells (PBMC) were isolated from blood samples by density-gradient centrifugation as reported previously [34]. The isolated PBMC were plated in 96 -well $U$ bottom plates $\left(2 \times 10^{6}\right.$ cells each well) and stimulated with or without HP-PRRSV2 MLV JXA1-R strain at a multiplicity of infection (MOI) of 0.01 for $20 \mathrm{~h}$. Brefeldin A (10 $\mu \mathrm{g} / \mathrm{mL}$, Sigma, MO, USA) was added during the last $5 \mathrm{~h}$ of incubation. After incubation, the cells were harvested and stained for cell surface marker and intracellular cytokine as we previously reported [35]. Briefly, cells were stained with PerCPCy5.5-conjugated anti-pig CD3 (clone 8E6-8C8, BD Bioscience) for $30 \mathrm{~min}$ on ice. After washing, the cells were fixed with $4 \%$ paraformaldehyde and permeabilized with $0.2 \%$ saponin twice, and then incubated with Alexa Fluor 647-conjugated anti-pig IFN- $\gamma$ (clone P2G10, BD Bioscience) or isotype matched control antibody for $20 \mathrm{~min}$. Flow cytometry was performed with a FACS LSRFortessa (BD Biosciences, NJ, USA) and a minimal number of 300 000 cells was acquired. Data analysis was processed by FlowJo software (Tree Star Inc.).

\section{Characterization of distinct nAb VDJ repertoires}

To characterize the swine VDJ repertoires associated with different PRRSV nAbs, in this study, we amplified the immunoglobulin heavy chain VDJ region from representative pigs producing distinct nAbs with a single pair of primers (pVDJ-FR1-F: 5'-ATGGAGTTTCGG CTGAACT-3' and pVDJ-FR4-R: 5'-TGAGGACACGAC GACTTCA-3) modified from our previous report [16]. The same strategies and criteria were used to analyze and select VDJ lineages potentially associated with different nAbs [16].

\section{Statistical analysis}

The data of virus load, antibody level, rectal temperature, weight gain, IFN- $\gamma$ concentration and percentage of IFN- $\gamma$ secreting cells are shown as means \pm standard deviations (SD). The differences between groups were determined by Mann-Whitney U test using Graphpad Prism version 6.07 [36]. A $p$ value $<0.05$ was considered statistically significant.

\section{Results}

ORF2-6-CON shares $>90 \%$ nucleotide identity to Chinese PRRSV2 isolates

A set of 30 representative Chinese PRRSV isolates was obtained from GenBank. The phylogenetic tree was 
constructed based on ORF2-6 genes of mainly Chinese PRRSV2 and some representative PRRSV1 strains. There are four lineages $(1,3,5$ and 8$)$ of PRRSV2 isolates coexisting in Chinese swine herds. The synthetic PRRSV2 ORF2-6-CON sequence was located at the center of the phylogenetic tree (Figure 1A), sharing $>90 \%$ nucleotide identities to all four lineages of PRRSV2 isolates and an increased nucleotide identity to PRRSV1 isolate (from 61.55 to $65.53 \%$ ) (Figure 1B).

\section{The rJS-ORF2-6-CON is infectious in vitro}

The rJSTZ1712-12 and rJS-ORF2-6-CON full-length cDNA clones were generated using the reverse-genetic system as we previously described (Figure 2) [25]. After five time passages in Marc-145 cells, typical PRRSV-specific cytopathic effects (CPE) could be observed at about 3-4 dpi. The presence of PRRSV was confirmed by IFA staining using cells infected for $48 \mathrm{~h}$. PRRSV-specific antigen was detected in JSTZ1712-12, rJSTZ1712-12 and rJS-ORF2-6-CON infected cells but not in mock infected Marc-145 cells (Figure 3A). Multiple-step growth curves showed that the growth kinetics of parental JSTZ171212 isolate is similar (slightly higher but not significantly different, $p>0.05$ ) to the cloned rJSTZ1712-12 and rJSORF2-6-CON viruses. The titers of all three viruses peaked at 96 hpi (Figure 3B). Furthermore, the rJSORF2-6-CON strain produced similar sizes of plaques as the backbone rJSTZ1712-12 virus and the parental JSTZ1712-12 isolate (Figure 3C). These results indicate that the cloned rJSTZ1712-12 and rJS-ORF2-6-CON viruses have similar in vitro growth characteristics to the parental JSTZ1712-12 isolate.

\section{The rJS-ORF2-6-CON is not pathogenic to piglets}

Our previous study has shown that JSTZ1712-12 isolate is not pathogenic to piglets [24]. To characterize the pathogenicity of rJS-ORF2-6-CON in pigs, pig inoculation experiments were performed. Compared with the mock infected pigs, pigs inoculated with 5th passage of rJS-ORF2-6-CON did not result in any obvious clinical signs, or increase the rectal temperature, or affect the weight gain within $42 \mathrm{dpi}$ (Figures $4 \mathrm{~A}$ and B). Pigs inoculated with rJS-ORF2-6-CON virus had similar virus growth kinetics, similar levels of antibody and IFN- $\gamma$ responses as in TJM-F92 vaccinated pigs (Figures 4C-E). These results indicate that the rJS-ORF2-6-CON virus is infectious in vivo, but is not pathogenic to piglets.

\section{rJS-ORF2-6-CON confers cross protection against a NADC30-like isolate}

To evaluate the cross protection capacity of rJS-ORF26-CON, pigs in the rJS-ORF2-6-CON inoculated group, TJM-F92 vaccinated group and a control group were all challenged with the virulent NADC30-like SD17-38 isolate at $42 \mathrm{dpi}$. After challenge, the rectal temperatures of rJS-ORF2-6-CON inoculated pigs and mock-infected pigs were always lower than $40{ }^{\circ} \mathrm{C}$, while the TJM-F92 vaccinated pigs and positive control pigs (only SD17-38 challenge) have significantly higher rectal temperatures (Figure 4A). Two out of the five TJM-F92 vaccinated pigs reached $\geq 40{ }^{\circ} \mathrm{C}$ (the highest of $41.1{ }^{\circ} \mathrm{C}$ ), and all positive control pigs reached $\geq 40{ }^{\circ} \mathrm{C}$ (the highest was 41.3 ${ }^{\circ} \mathrm{C}$ ). Clinical symptoms including dyspnea, anorexia and diarrhea were observed in the positive control pigs and two TJM-F92 vaccinated pigs (pigs 9 and 10), but not in mock-infected or rJS-ORF2-6-CON inoculated pigs. In addition, the weight gain of rJS-ORF2-6-CON inoculated pigs was not significantly different from the negative control group, but was significantly higher than TJM-F92 vaccinated pigs at $14 \mathrm{dpc}$ (Figure $4 \mathrm{~B}$ ). SD17-38 virus was detected at $4 \mathrm{dpc}$ in all challenged pigs, but the viremia was significantly lower in rJS-ORF2-6-CON inoculated pigs than in TJM-F92 vaccinated pigs since $7 \mathrm{dpc}$ and could be eliminated within $11 \mathrm{dpc}$ (Figure 4C).

During the necropsy, lung consolidation was observed in positive control pigs and two TJM-F92 vaccinated pigs but not in mock-infected pigs or rJS-ORF2-6-CON inoculated pigs (Figures 5A-D). In addition, histopathological examination shows that interstitial pneumonia with infiltration of mononuclear cells was observed in the lungs from positive control pigs and TJM-F92 vaccinated pigs (Figures 5E-H). Furthermore, PRRSV antigen was detected in all challenged pigs but not in mock-infected pigs during the immunohistochemical examination (Figures $5 \mathrm{I}-\mathrm{L}$ ). The corresponding viruses in pigs during inoculation or challenge experiments were all confirmed by sequencing (data not shown). These results demonstrate that rJS-ORF2-6-CON confers better cross protection against virulent NADC30-like isolate than the TJM-F92 vaccine.

\section{The rJS-ORF2-6-CON induces similar frequency of PRRSV-specific IFN- $\gamma$ secreting cells as the TJM-F92 vaccine}

To evaluate the role of IFN- $\gamma$ secreting cells in conferring cross protection, the frequencies of PRRSV-specific IFN- $\gamma$ secreting cells in PBMC were tested by flow cytometric analyses. At $42 \mathrm{dpi}(0 \mathrm{dpc})$, the frequencies of PRRSV-specific IFN- $\gamma$ secreting cells was low and no significant difference was detected among all the groups. After challenge with the virulent SD17-38 isolate, the frequencies of PRRSV-specific IFN- $\gamma$ secreting cells increased from 0 to $14 \mathrm{dpc}$. However, no difference was noticed between TJM-F92 vaccinated and rJS-ORF2-6$\mathrm{CON}$ inoculated pigs (Figure 6). In addition, no significant difference was detected in IFN- $\gamma$ concentrations of 
A

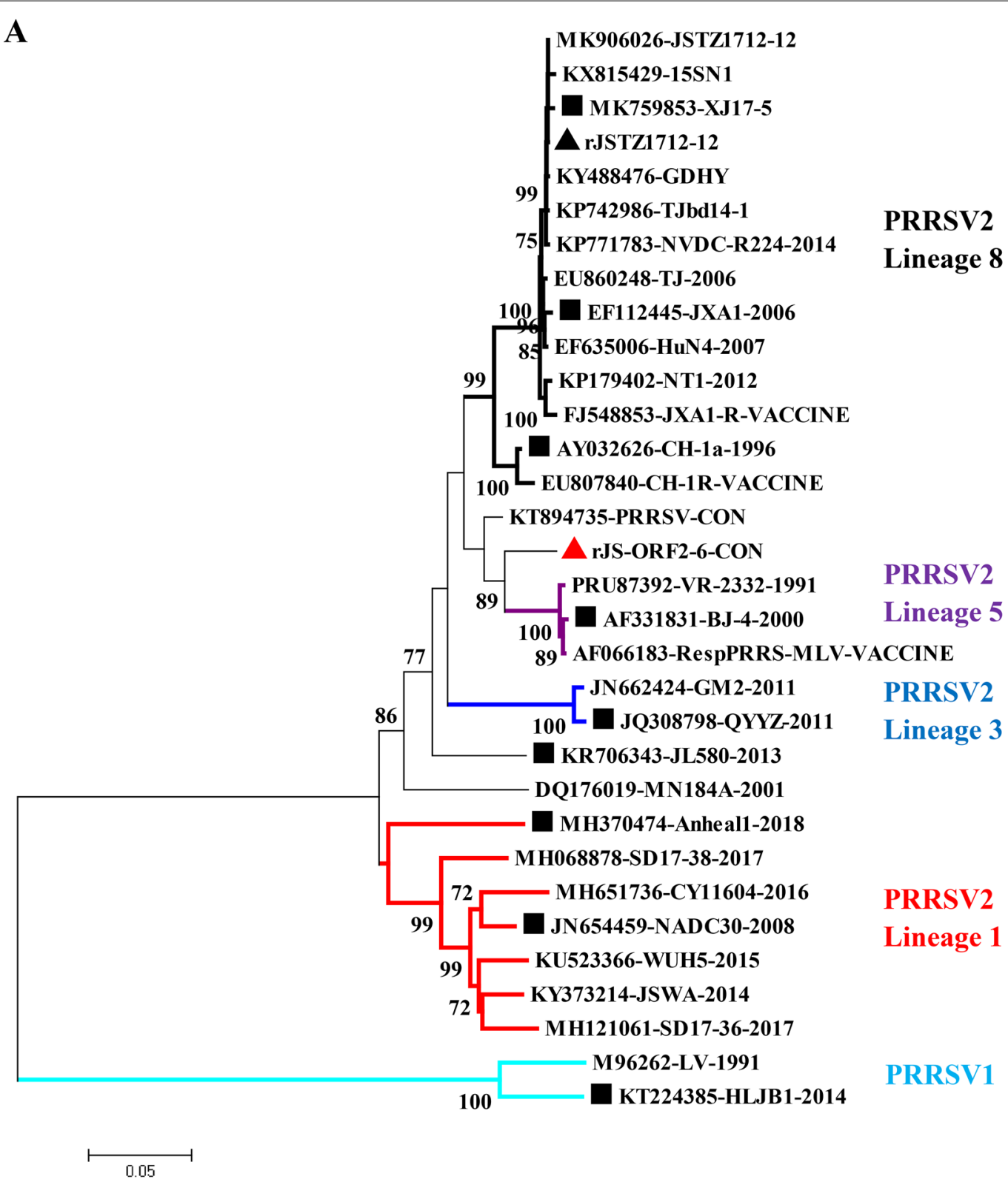

B

Nucleotide identities between ORF2-6-CON and ORF2-6 from representative PRRSV isolates

\begin{tabular}{|c|c|c|c|c|c|c|c|c|c|}
\hline & \multicolumn{8}{|c|}{ PRRSV2 } & \multirow[t]{2}{*}{ PRRSV1 } \\
\hline & Lineage & & & Lineage 5 & Lineage 3 & Lineag & & & \\
\hline & $\mathrm{XJ} 17-5$ & JXA1 & $\mathrm{CH}-1 \mathrm{a}$ & BJ-4 & QYYZ & JL580 & NADC30 & Anheal1 & HLJB1 \\
\hline rJSTZ1712-12 & 99.72 & 99.19 & 96.18 & 91.26 & 89.46 & 90.87 & 85.99 & 86.06 & 61.55 \\
\hline ORF2-6-CON & 91.37 & 91.44 & 93.77 & 94.73 & 90.77 & 90.38 & 90.20 & 90.94 & 65.53 \\
\hline
\end{tabular}

Figure 1 Design of the consensus sequence of ORF2-6 genes (ORF2-6-CON). The ORF2-6-CON was designed according to 30 representative Chinese PRRSV isolates. A phylogenetic tree based on ORF2-6 genes was constructed (A). The ORF2-6-CON shared $>90 \%$ nucleotide identities to all four lineages of PRRSV2 isolates existing in China (B). 
$\mathbf{A}$
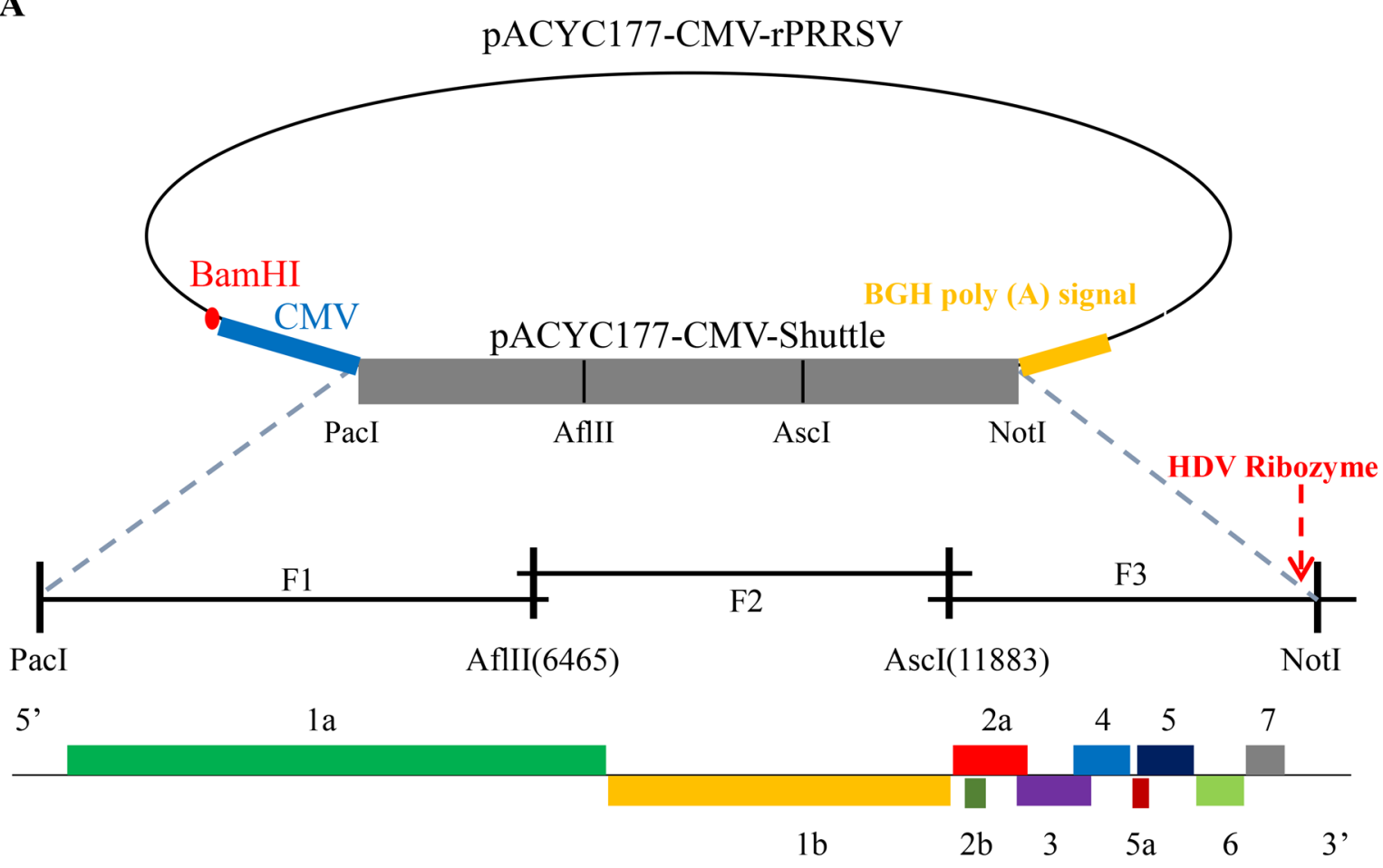

rJSTZ1712-12

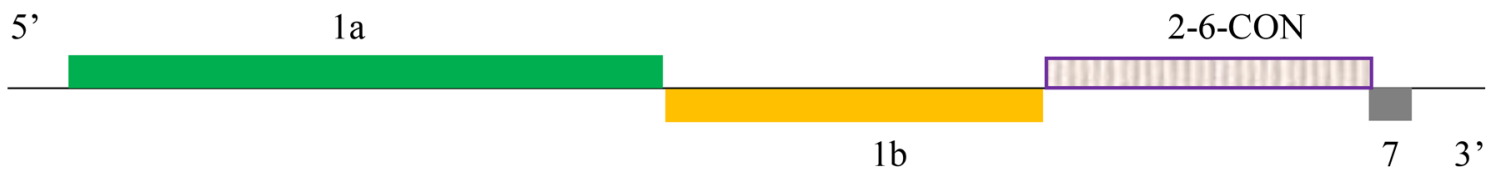

rJS-ORF2-6-CON
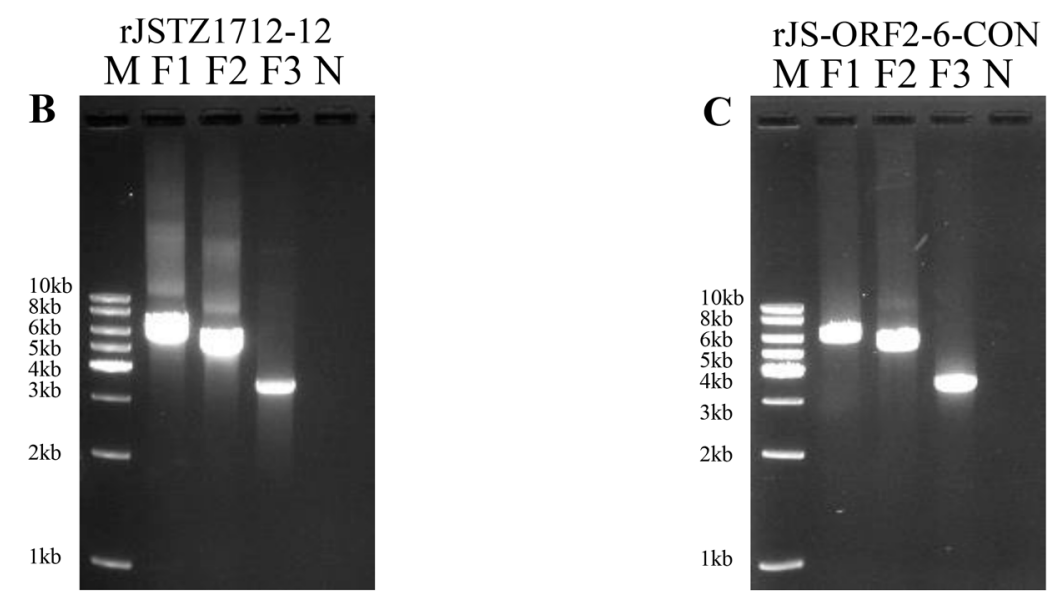

Figure 2 Strategy to construct the full-length cDNA clones of avirulent HP-PRRSV2 JSTZ1712-12 isolate and a chimeric virus containing ORF2-6-CON. The strategy was adopted from our previous study [25]. The pACYC177-CMV-Stuffer fragment including the unique restriction enzymes was shown in the upper part (A). The three overlapped fragments of the rJSTZ1712-12 (B) and rJS-ORF2-6-CON (C) genomes were produced by PCR amplification and are shown in the bottom part. 
sera from TJM-F92 vaccinated and rJS-ORF2-6-CON inoculated pigs at $0 \mathrm{dpc}$ and $14 \mathrm{dpc}$ (Figure 4E).

\section{rJS-ORF2-6-CON induces antibodies with broadly neutralizing activity}

To explore the role of nAbs in conferring cross protection, a virus neutralization test was performed for the 42 dpi $(0 \mathrm{dpc})$ sera. No nAbs was found in any mockinfected pigs. One out of five pigs (pig 6) immunized with TJM-F92 vaccine induced homologous nAbs against HP-PRRSV2. Three out of five pigs (pigs 12, 13 and 14) inoculated with rJS-ORF2-6-CON virus induced heterologous nAbs against different lineages of PRRSV2 isolates (lineages 8, 5 and/or 1). Remarkably, pig 12 serum could neutralize not only distinct PRRSV2 isolates but also PRRSV1 isolate (Table 2). Therefore, pig 12 serum was described as possessing a broad neutralizing activity. Noticeably, the titers of nAbs in pigs 6, 12, 13, 14 increased but their neutralization activities did not change at $14 \mathrm{dpc}$ (data not shown).

To further characterize VDJ repertoires associated with different PRRSV nAbs, the VDJ genes were amplified from two separate aliquots of each lymph node from four pigs secreting nAbs (pigs 6, 12, 13 and 14) and a mock infected pig (pig 3) as the control. A total of 271 swine VDJ sequences were obtained, including 55, 68, 56, 52 and 40 sequences from pig 3 that produced no nAbs, pig 6 for homologous nAbs, pig 12 for bnAbs, and pigs 13 and 14 for heterologous nAbs, respectively. All the swine VDJ sequences from this study have been submitted to GenBank (MW460272-MW460542). The alignment of VDJ sequences indicates that the divergence of swine VDJ genes was mainly due to high variation of the CDR (Additional file 1), which was consistent with previous reports $[16,37]$. The diversification of the CDR was not only due to the high mutation rate but also to the change in length. The length of CDR1 was 5 aa, CDR2 was 7-9 aa, while CDR3 was 9-21 aa (Table 3).

Capture-recapture analysis using two separate aliquots from the same pig lymph node was performed to refine the PRRSV activated B-cell clones [38]. Shared or identical sequences were identified in mock-infected pig 3 but were less abundant ( $<3$ sequences). Therefore, no sequence from the mock-infected pig met the criteria as we described previously [16]. In PRRSV-infected pigs, the most shared and abundant VDJ sequences were found in bnAbs pig 12 that has only one lineage including six highly similar CDR3, which met the shared and abundant criteria. Another lineage that met the criteria was identified in heterologous nAbs pig 14 with 3 identical CDR3. Even though shared sequences were also detected in pigs 6 and 13, they were not abundant with only two identical sequences. No lineage met the criteria found in pigs
6 and 13, which was probably due to not enough high depth coverage of sequencing.

\section{Discussion}

Traditional PRRS vaccines cannot provide sufficient cross protection against high genetic divergent PRRSV isolates. Therefore, genetic engineering approaches have been widely applied to generate broadly protective vaccine candidates $[11,23]$. In this study, we describe the generation of a chimeric HP-PRRSV2 virus containing a consensus sequence of PRRSV2 ORF2-6 genes, which could induce bnAbs and confer cross protection against a heterologous NADC30-like PRRSV2 isolate.

To overcome the big challenge caused by the substantial genetic diversity of PRRSV, multiple strategies have been employed in the last three decades. A multi-strain vaccine constructed based on five attenuated PRRSV strains was evaluated in pigs, which did not provide an improved cross protection compared with the singlestrain vaccine and which might have a safety issue [39]. A chimeric PRRSV based on two field strains could confer better protection against both viruses but its efficiency against other heterologous strains was not tested [40]. DNA shuffling of individual envelope encoding genes (ORF3, ORF4, ORF5, ORF6) from multiple strains could generate chimeric viruses with improved cross-neutralizing antibodies [20-22]. The chimeric virus containing shuffled ORF3-6 genes conferred an enhanced cross protection in pigs against NADC20 and RFLP 1-7-4 strains [41]. A consensus PRRSV genome was designed using the strategy of centralized sequences based on 59 PRRSV2 genomes. The generated PRRSV-CON strain is highly virulent but it could confer significantly broader levels of heterologous protection than the wild-type strain [11]. In this study, we synthesized an ORF2-6 consensus sequence of PRRSV2 encoding all envelope proteins. The infectious clone of avirulent HP-PRRSV2 JSTZ1712-12 strain was used as the backbone to generate a chimeric virus containing the ORF2-6-CON. The rJS-ORF2-6$\mathrm{CON}$ strain was not pathogenic in pigs, it might induce bnAbs and could confer cross protection against the virulent NADC30-like SD17-38 isolate. Our results indicate that rJS-ORF2-6-CON may be a promising candidate for the development of a broadly protective PRRS vaccine.

A huge amount of PRRSV strains has been isolated in Chinese swine herds. PRRSV2 is predominant since its emergence in 1995 and causes several outbreaks in the last two decades [7, 8, 42, 43]. The HP-PRRS pandemic caused by HP-PRRSV2 has seriously prejudiced the development of the Chinese swine industry since 2006 [7]. In 2013, the emergence of NADC30-like PRRSV in China caused enormous losses due to the limited cross protection of commercial PRRS vaccines against 


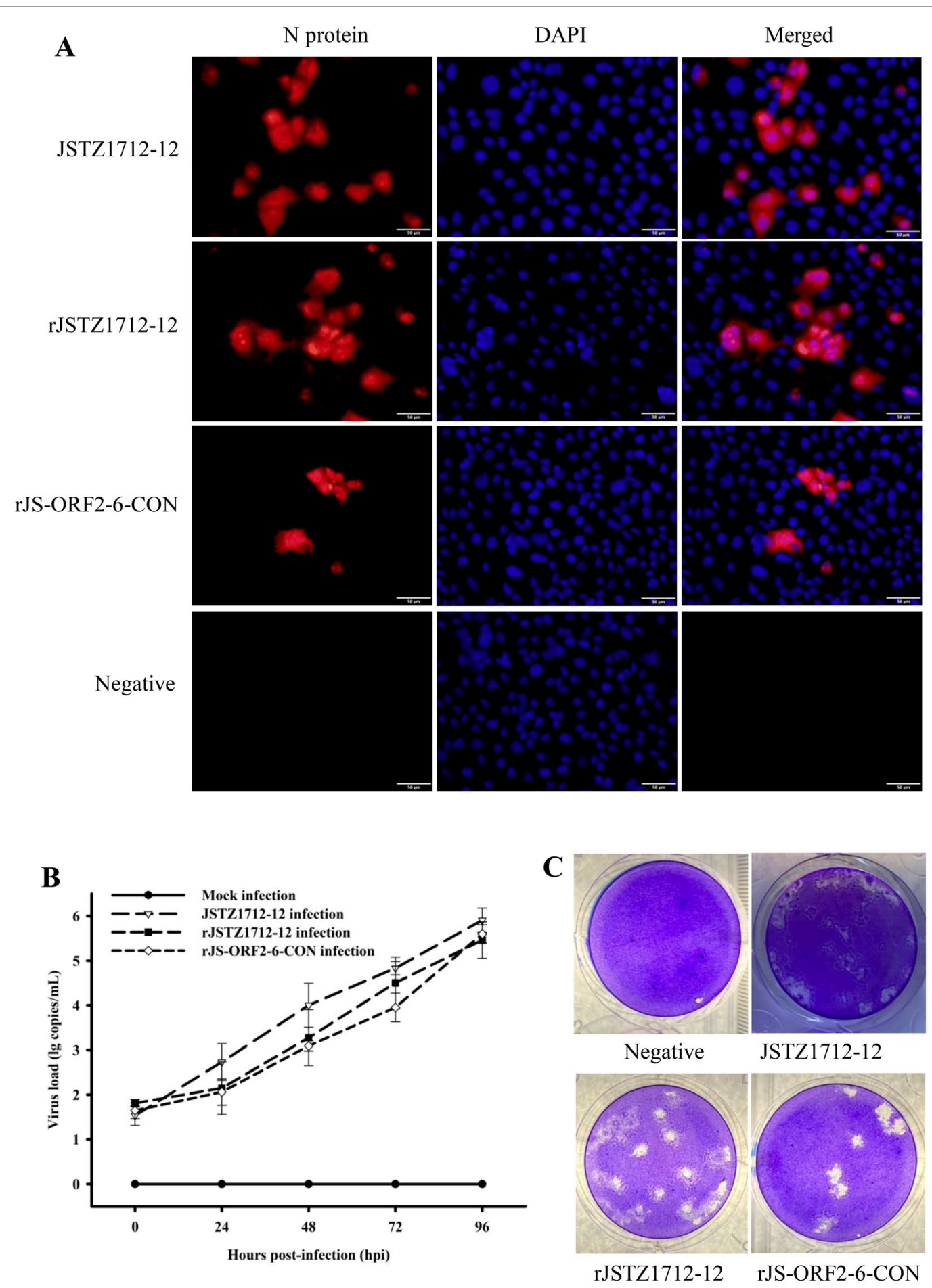

Figure 3 Identification of the rescued rJSTZ1712-12 and rJS-ORF2-6-CON in vitro. PRRSV-specific antigen was detected by the immunofluorescence assay (IFA) (A). The multiple-step growth curves in Marc-145 cells within 96 hpi were determined by real-time RT-PCR assay [32]. No significant difference was observed in the in vitro replication of the parental and cloned viruses (B). The JSTZ1712-12, rJSTZ1712-12 and rJS-ORF2-6-CON viruses have similar plaque morphology (C). 

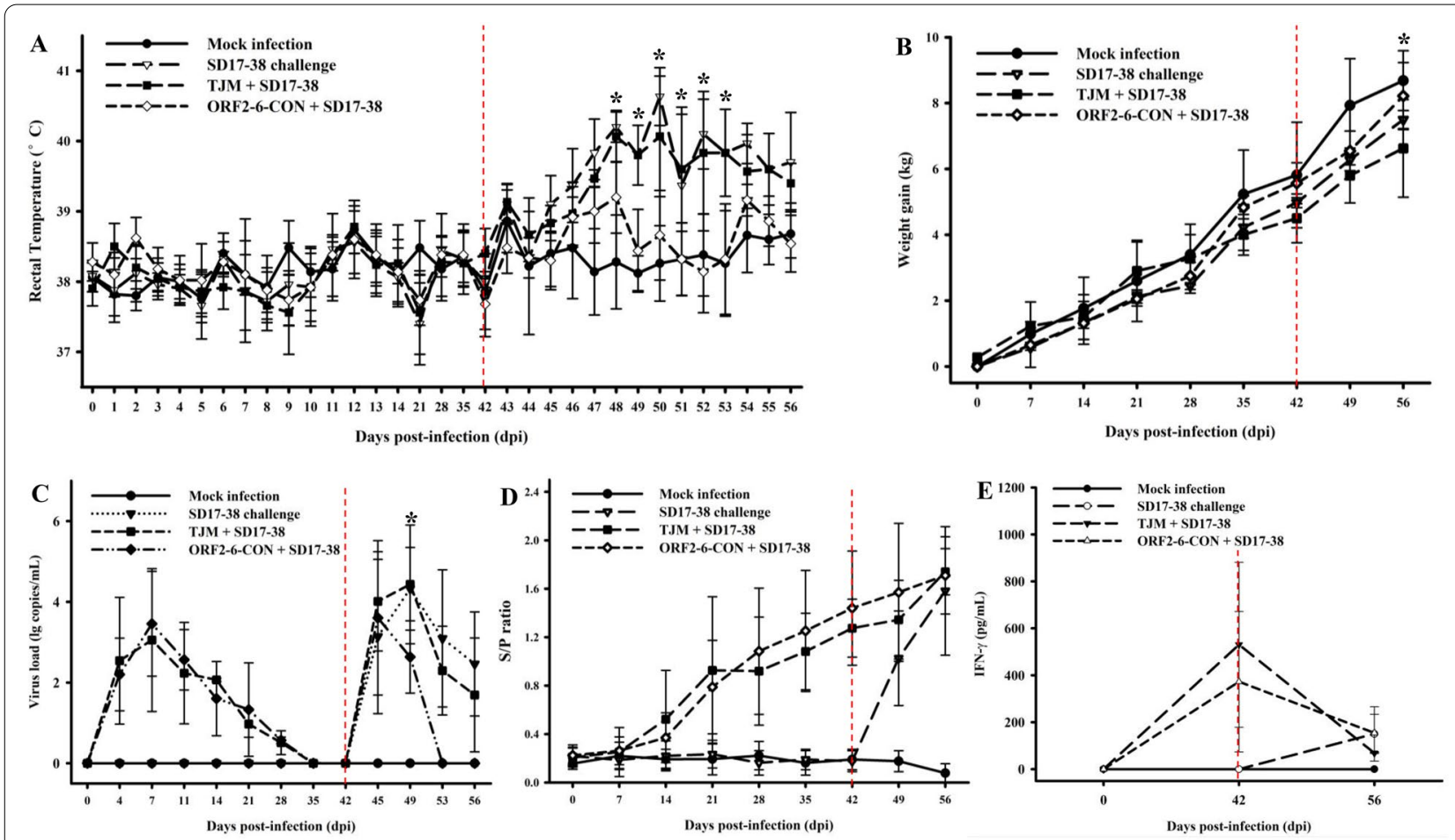

Figure 4 Dynamics of rectal temperature, weight gain, virus load, antibody and IFN- $\gamma$ levels during inoculation and challenge studies. After the challenge of NADC30-like SD17-38 isolate, all positive control pigs and two of TJM-F92 vaccinated pigs showed high fever. However, the rectal temperature of rJS-ORF2-6-CON inoculated and mock-infected pigs did not reach $40^{\circ} \mathrm{C}$ during the whole experiment (A). rJS-ORF2-6-CON inoculated pigs had significantly higher weight gain than TJM-F92 vaccinated pigs at $14 \mathrm{dpc}$ (B). Dynamics of viremia were detected by real-time RT-PCR assay [32]. Compared with TJM-F92 vaccinated pigs, the virus load was significantly lower in rJS-ORF2-6-CON inoculated pigs since 7 dpc (C). PRRSV-specific antibody level was detected by IDEXX HerdCheck*PRRS $\times 3$ Antibody Detection ELISA Kit. The threshold for seroconversion was set at a sample-to-positive ( $/ / p$ ) ratio of 0.4. PRRSV-specific antibody could be detected in all PRRSV-infected pigs from 14 dpi to the end of the study (D). IFN- $\gamma$ level was detected using a commercial Porcine IFN-gamma ELISA kit. No significant difference of IFN- $\gamma$ amounts was detected in rJS-ORF2-6-CON inoculated and TJM-F92 vaccinated pigs at $42 \mathrm{dpi}$ and $14 \mathrm{dpc}$ (E). Each bar represents the average for all pigs in each group \pm standard deviation (SD). The significant difference is marked with an asterisk.

NADC30-like isolates [8, 44-46]. Currently, the prevalent Chinese PRRSV2 isolates can be divided into four lineages (lineages 1, 3, 5 and 8) [47]. In addition, PRRSV1 isolates have been detected in more than ten provinces and have evolved into at least four subgroups in China $[26,30,48]$. The co-existence of highly divergent PRRSV isolates makes the control of PRRS more complicated and difficult in China. Here we designed an ORF2-6 consensus sequence based on 30 Chinese PRRSV isolates representing different species and lineages. Intriguingly, the chimeric virus could induce bnAbs against both PRRSV1 and different lineages of PRRSV2 isolates.

Previous studies demonstrated that nAbs plays a critical role in PRRSV protective immunity $[49,50]$. Passive transfer of PRRSV nAbs alone could fully prevent the transplacental infection with PRRSV and provide sterilizing immunity in vivo [50]. Multiple neutralizing epitopes have been identified among PRRSV major and minor envelope proteins. Several studies showed that minor glycoproteins GP2, GP3 and GP4 of PRRSV1 strains possess neutralizing epitopes, while GP5 and M heterodimers of PRRSV2 strains are the major target for viral neutralization $[15,51]$. PRRSV infection might induce homologous nAbs, heterologous nAbs and bnAbs [13, 17]. Remarkably, pigs exposed to circulating field PRRSV strains could induce bnAbs against both PRRSV1 and PRRSV2 [12]. Our previous studies also showed that $~ 1 \%$ of experimentally infected pigs could produce bnAbs [13, 16]. However, what strategy should be used to induce bnAbs remains unclear. In this study, we show that the rJS-ORF2-6-CON strain could induce heterologous nAbs or even bnAbs. The results demonstrate that the designation of a consensus sequence encoding all PRRSV envelope proteins could be an alternative strategy to inducing broader cross-neutralizing antibodies. In addition, this chimeric virus may be a useful tool to identify the exact epitope/residue involved in inducing distinct nAbs.

Pigs that produce homologous nAbs, heterologous nAbs and bnAbs provide an ideal opportunity to explore swine $B$ cell repertoires associated with different $n A b$ 


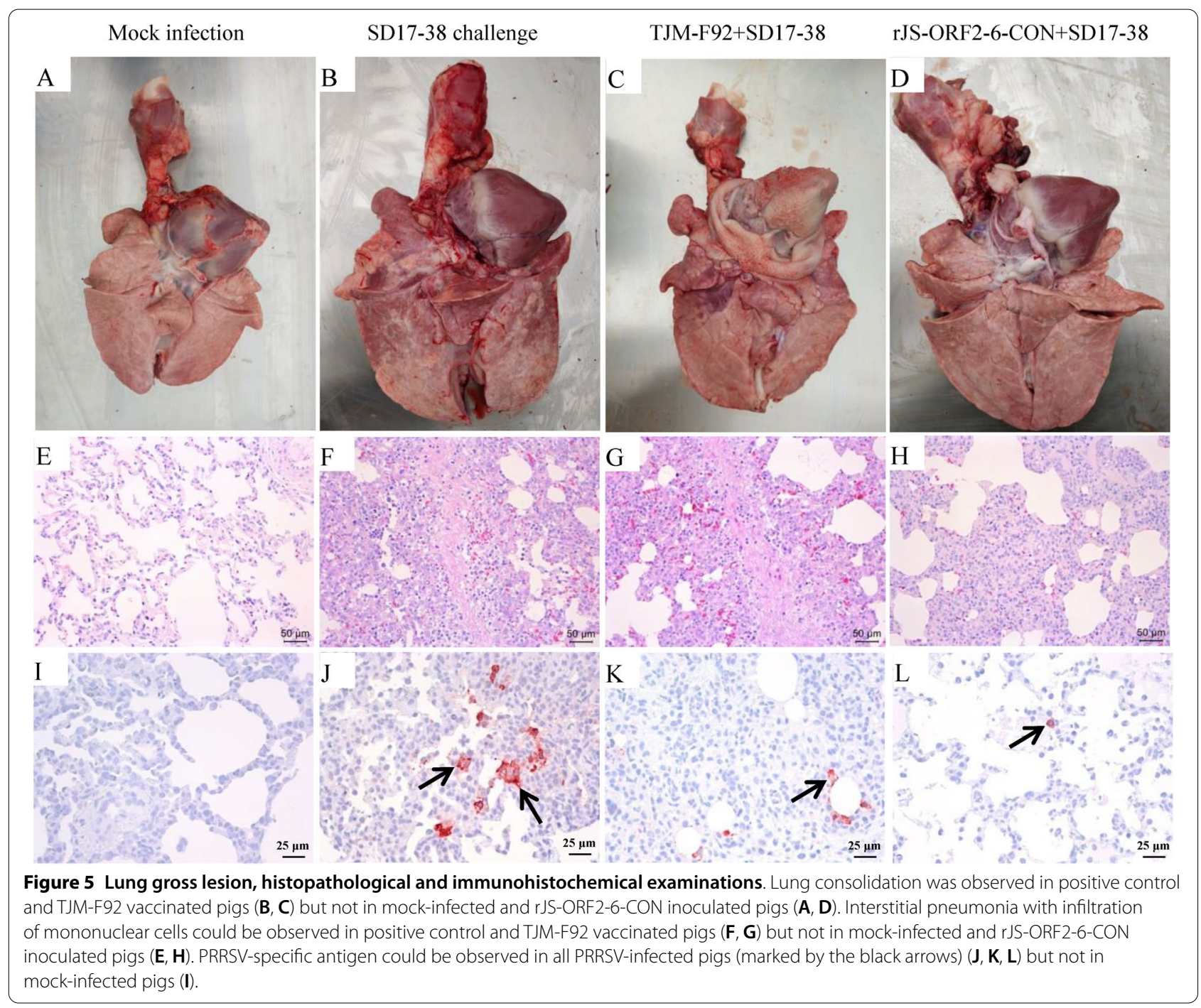

responses. To elicit immune response to unlimited numbers of foreign antigens, the immune system must recognize countless numbers of antigens. The unlimited numbers of unique antigen receptors are achieved by creating variation in the antigen-recognition regions [52]. The mechanisms mainly involve mixing and matching variable $(V)$, diversity $(D)$, and joining $(J)$ gene segments in a process called V(D)J recombination. Antigen-binding specificity of an antibody is primarily determined by its heavy chain variable regions [53]. Only a few genes are involved in antibody production in pigs. Swine utilize seven major $\mathrm{V}_{\mathrm{H}}$ genes $\left(\mathrm{V}_{\mathrm{H}} \mathrm{A}, \mathrm{V}_{\mathrm{H}} \mathrm{B}, \mathrm{V}_{\mathrm{H}} \mathrm{C}, \mathrm{V}_{\mathrm{H}} \mathrm{E}, \mathrm{V}_{\mathrm{H}} \mathrm{F}, \mathrm{V}_{\mathrm{H}} \mathrm{Y}\right.$, $\mathrm{V}_{\mathrm{H}} \mathrm{Z}$ ), two $\mathrm{D}_{\mathrm{H}}$ segments and a single $\mathrm{J}_{\mathrm{H}}$ gene to account for nearly its entire $(>90 \%)$ VDJ pre-immune repertoire [54]. Furthermore, exposure to environmental antigen does not change the $V_{H}$ genes that comprise the preimmune repertoire. The same $\mathrm{V}_{\mathrm{H}}$ genes comprise the adaptive repertoire but $\sim 90 \%$ of them are somatically mutated [54]. These unique features provide an opportunity to analyze the porcine antibody repertoire by detecting the entire VDJ repertoire using a single primer set [16]. In this study, we determined shared and abundant VDJ genes from pigs secreting bnAbs and heterologous nAbs, these shared and abundant sequences were likely expressed by B cells activated by PRRSV infection. B cells from different lymphoid tissues of a PRRSV-infected pig sampled at the same time displayed a similar pattern, indicating the widespread dissemination of the same $B$ cell clones [55-57]. Therefore, B cell repertoires of the lymph nodes could represent the entire B cell repertoires 


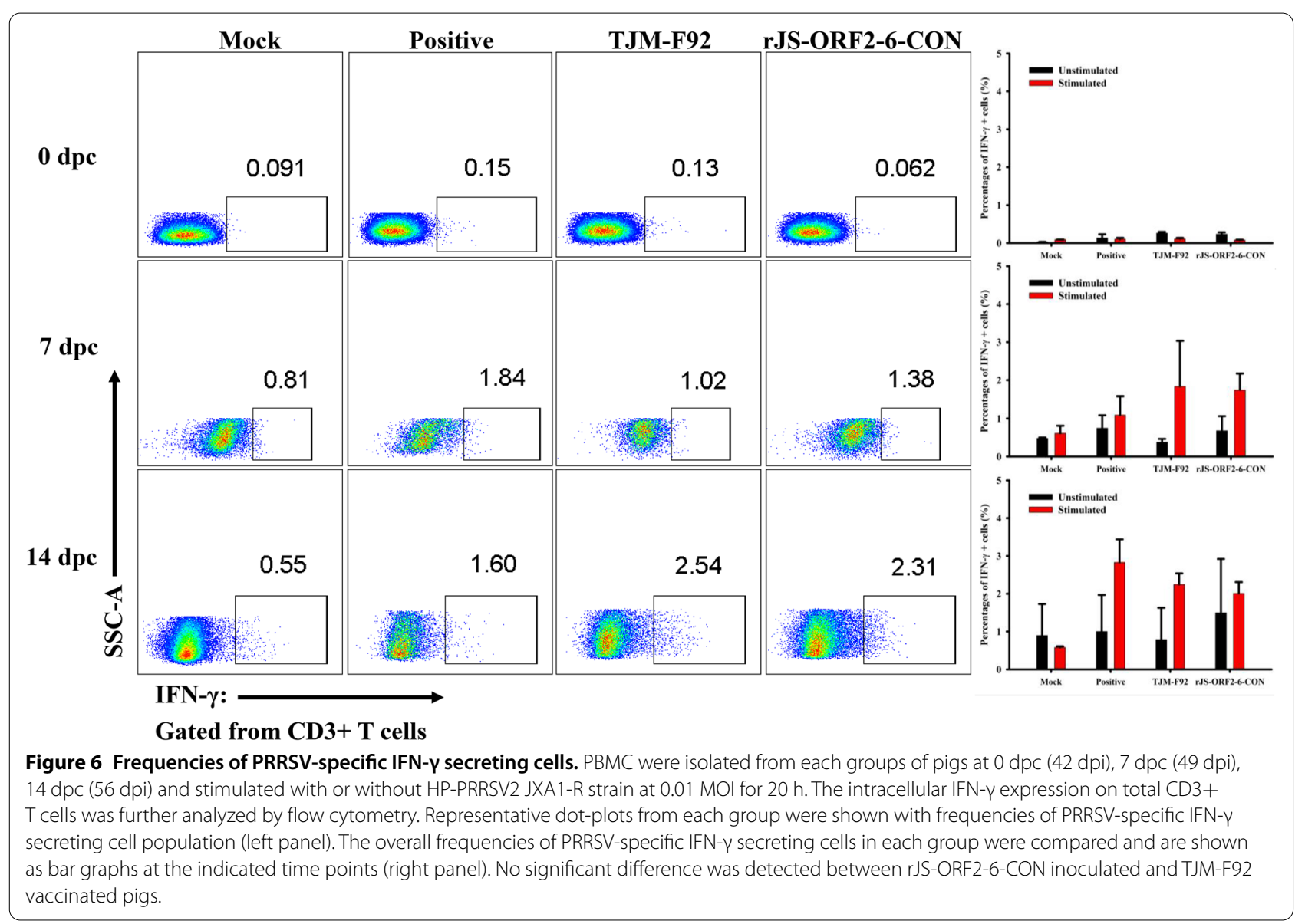

of PRRSV-infected pigs, suggesting that the shared and abundant sequences in these pigs were potentially correlated with the different $\mathrm{nAb}$ responses. However, further studies, such as the construction of single-domain antibodies, need to be executed to determine whether the shared and abundant VDJ lineages identified in this study are PRRSV-specific or distinct nAbs-associated.

Cross protection is extremely important due to the coexistence of distinct PRRSV isolates. However, by which mechanisms to confer protection by PRRSV are poorly understood [58]. PRRSV-specific IFN- $\gamma$ producing cells have been suggested to be correlated with vaccine-induced protection [59]. However, the degrees of correlation between the frequencies of PRRSV-specific IFN- $\gamma$ secreting cells and the levels of protection are highly variable [60]. In this study, rJS-ORF2-6-CON could confer better cross protection than the TJM-F92 vaccine, but no significant difference was detected in
IFN- $\gamma$ secreting cells and IFN- $\gamma$ production by these two groups of pigs. In contrast, rJS-ORF2-6-CON could induce heterologous nAbs or even bnAbs while TJMF92 only induced homologous nAbs. These results indicate that nAbs play a critical role in conferring cross protection. Passive transfer studies provided direct evidence that $\mathrm{nAbs}$ alone can protect pigs against PRRSV infection $[49,50]$. It would be interesting to evaluate whether heterologous nAbs or bnAbs alone can provide cross protection or whether they need assistance from other immune factors in the future.

Even though protection efficiency is a vital criterion for breeding next generation PRRS vaccines, safety is another major concern that is at least as important as protection efficiency. Persistent MLV infection in vaccinated pigs and transmission of vaccine strains to naïve pigs have been confirmed [27, 51, 61]. In addition, MLV-derived field isolates and recombinants from 
Table 2 Virus neutralization properties of sera with distinct neutralization activities.

\begin{tabular}{|c|c|c|c|c|}
\hline \multirow[t]{2}{*}{ PRRSV subgroups } & \multirow[t]{2}{*}{ Representative isolates } & \multirow{2}{*}{$\begin{array}{l}\text { Mock inoculation } \\
\text { Pig } 3\end{array}$} & \multirow{2}{*}{$\begin{array}{l}\text { TJM-F92 inoculation } \\
\text { Pig } 6\end{array}$} & \multirow{2}{*}{$\begin{array}{l}\text { rJS-ORF2- } \\
6 \text {-CON } \\
\text { inoculation } \\
\text { Pig } 12\end{array}$} \\
\hline & & & & \\
\hline \multirow[t]{2}{*}{ JXA1-like HP-PRRSV2 } & $\begin{array}{l}\text { JSTZ1712-12 } \\
(\text { MK906026) } \\
(99 / 92)^{a}\end{array}$ & $<8^{b}$ & 64 & 32 \\
\hline & $\begin{array}{l}\text { JXA1-R } \\
\text { (MT163314) } \\
(99 / 91)\end{array}$ & $<8$ & 32 & 16 \\
\hline \multirow[t]{2}{*}{ CH-1a-like PRRSV2 } & $\begin{array}{l}\text { SD1612-1 } \\
\text { (MN1 19304) } \\
(96 / 93)\end{array}$ & $<8$ & $<8$ & 32 \\
\hline & $\begin{array}{l}\text { CH-1R } \\
\text { (EU807840) } \\
(96 / 93)\end{array}$ & $<8$ & $<8$ & 16 \\
\hline \multirow[t]{2}{*}{ VR-2332-like PRRSV2 } & $\begin{array}{l}\text { JSYC20-05-1 } \\
(\text { MT746146) } \\
(92 / 94)\end{array}$ & $<8$ & $<8$ & 16 \\
\hline & $\begin{array}{l}\text { R98 } \\
\text { (DQ355796) } \\
(92 / 94)\end{array}$ & $<8$ & $<8$ & 16 \\
\hline \multirow[t]{2}{*}{ NADC30-like PRRSV2 } & $\begin{array}{l}\text { SD17-36 } \\
(\mathrm{MH} 121061) \\
(86 / 90)\end{array}$ & $<8$ & $<8$ & 8 \\
\hline & $\begin{array}{l}\text { SD17-38 } \\
\text { (MH068878) } \\
(85 / 90)\end{array}$ & $<8$ & $<8$ & 16 \\
\hline NADC34-like PRRSV2 & $\begin{array}{l}\text { Anheal-1 } \\
(\mathrm{MH} 370474) \\
(86 / 90)\end{array}$ & $<8$ & $<8$ & 8 \\
\hline PRRSV1 & $\begin{array}{l}\text { HLJB1 } \\
\text { (KT224385) } \\
(61 / 65)\end{array}$ & $<8$ & $<8$ & 8 \\
\hline
\end{tabular}

MLV and wild-type strains have been isolated [26, 62]. Moreover, some MLV-like isolates (NT1, JX2014T2 and XJ17-5) are highly virulent viruses determined by animal challenge studies [24, 63, 64]. Therefore, more attention should be paid to PRRS vaccine safety. Even though the preliminary results from this study show that rJS-ORF2-6-CON is not pathogenic to piglets, systematic safety tests must be performed to decide whether it can be used as a vaccine in pigs.

In conclusion, an ORF2-6 consensus sequence was computationally designed based on a large amount of representative Chinese PRRSV isolates in this study. The chimeric virus containing this consensus sequence is not pathogenic to piglets, may induce bnAbs and confers better cross protection against heterologous NADC30-like isolate than a commercial MLV vaccine. The chimeric virus may serve as a promising candidate for developing broadly protective PRRS vaccine. In addition, this chimeric virus can be used to investigate the mechanisms involved in inducing bnAbs or conferring cross protection. 
Table 3 VDJ sequences with identical or high similar CDR3 from four pigs.

\begin{tabular}{|c|c|c|c|c|c|}
\hline Pig & No & Name & CDR1 & CDR2 & CDR3 \\
\hline \multirow[t]{6}{*}{ Pig 3} & 1 & $3-\mathrm{R3}$ & SYAVS & YIGSSGR & ARGLAYGAIMDL \\
\hline & & $3-F 18$ & $\ldots$ & $\ldots \ldots$ & $\ldots$ \\
\hline & 2 & $3-F 13$ & STGII & EVTEDGGL & TLYLTYLDL \\
\hline & & $3-F 23$ & $\ldots$ & $\ldots \ldots$ & $\ldots \ldots \ldots$ \\
\hline & 3 & $3-R 29$ & SYEIS & GVDGDRWSG & $\begin{array}{l}\text { AGCPLYSGCYIGQLG- } \\
\text { GVMDL }\end{array}$ \\
\hline & & $3-R 40$ & $\ldots$ & $\ldots$. & $\ldots \ldots \ldots$ \\
\hline \multirow[t]{6}{*}{ Pig 6} & 1 & $6-\mathrm{R} 10$ & DNAFS & AIASSDYDG & $\begin{array}{l}\text { AIG-CYSYGASCYGSYYY- } \\
\text { AMDL }\end{array}$ \\
\hline & & $6-\mathrm{F} 20$ & $\ldots$ & $\ldots \ldots \ldots$ & $. . Q N \ldots \ldots \ldots . . . D Q P--T \ldots$ \\
\hline & 2 & $6-R 27$ & GSYIN & TISSSGG & ATGLSMVLVAWGAMDL \\
\hline & & $6-F 28$ & $\ldots$ & $\ldots \ldots$ & $\ldots \ldots \ldots \ldots \ldots$ \\
\hline & 3 & $6-F 15$ & DYAFS & AIASSDYDG & $\begin{array}{l}\text { ASAVAIAVTFGGRQQYY- } \\
\text { AMDL }\end{array}$ \\
\hline & & $6-\mathrm{F} 17$ & $\ldots$ & & $\ldots \ldots \ldots$ \\
\hline \multirow[t]{6}{*}{ Pig 12} & $1^{\mathrm{a}}$ & $12-R 3^{b}$ & SYGVV & GIRIS-ISG & AGCAEYYFPYYYSVDL \\
\hline & & $12-\mathrm{R} 10$ & ..A.S & ..DSGSY. & ....W.....M. \\
\hline & & 12-R19 & & .....S. & ...N.W........ \\
\hline & & $12-\mathrm{R} 28$ & $. . A . S$ & ..DSGSY. & ....W.....M. \\
\hline & & $12-\mathrm{F} 3$ &.$V_{\ldots}$ & A $\ldots \ldots$ & ............ \\
\hline & & $12-\mathrm{F} 5$ &.$V_{\ldots}$ & $A \ldots \ldots$ & ............ \\
\hline \multirow[t]{4}{*}{ Pig 13} & 1 & $13-\mathrm{R} 10$ & STYIN & FIGTGGA & ARGGCYIGYNCYDMHL \\
\hline & & $13-F 12$ & $\cdots$ & $\ldots \ldots$ & $\ldots \ldots \vee \ldots \ldots \ldots$ \\
\hline & 2 & 13-R18 & DYAFN & GTSKSDYDS & AVGGATIAVAIAVPNAMDL \\
\hline & & $13-F 7$ & $\ldots$ & $\ldots \ldots \ldots$ & \\
\hline \multirow[t]{14}{*}{ Pig 14} & 1 & 14-R14 & SDPIG & RIFSGVS & AAYYEDTMHL \\
\hline & & $14-F 2$ & $\ldots$ & $\ldots \ldots$ & $\ldots \ldots \ldots$ \\
\hline & & 14-F16 & $\ldots$ & $\ldots \ldots$ & $\ldots \ldots \ldots$ \\
\hline & 2 & 14-R6 & SYEIS & GIVSTGS & ARIAIPMVLAIPPYYTMHL \\
\hline & & 14-R11 & $\cdots$ & $\ldots \ldots$ & . \\
\hline & & 14-R17 & $\ldots$ & $\ldots \ldots$ & .......... \\
\hline & 3 & $14-\mathrm{R} 10$ & DTYIS & TISTADA & ARRDSGCANSYVD \\
\hline & & 14-F19 & $\ldots$ & $\ldots \ldots$ & $\ldots \ldots \ldots \ldots$ \\
\hline & 4 & $14-\mathrm{R} 1$ & RTYIN & AISIGGV & ARDDFSDYCSASVCGMEL \\
\hline & & $14-R 12$ &.$H D$ & $\ldots \ldots$ & $\cdots$ \\
\hline & 5 & 14-F1 & SYPIG & DTSTSGG & ATGLMVLSSRTYGAMDL \\
\hline & & $14-\mathrm{F5}$ & $\ldots$ & $\ldots \ldots$ & ............. \\
\hline & 6 & 14-F11 & RYEVT & GIDDGTG & AMSYTYGISYDYCGMDR \\
\hline & & 14-F14 & $\ldots$ & $\ldots \ldots$ & ..G.S... \\
\hline
\end{tabular}

${ }^{a}$ The shared and abundant sequences ( $\geq 3$ sequences) are highlighted in red. The dot (.) means identical to the first aligned sequence. The short line (-) indicates a deletion. The column No. means the numbers of identical sequences from each pig.

${ }^{\mathrm{b}}$ The names of $\mathrm{VDJ}$ sequences starting with $\mathrm{R}$ or $\mathrm{F}$ indicate that they are from two different aliquots. The following number denotes the obtained sequence number.

\section{Abbreviations}

PRRSV: Porcine reproductive and respiratory syndrome virus; HP-PRRSV2: Highly pathogenic porcine reproductive and respiratory syndrome virus 2; HIV: Human immunodeficiency virus; nAbs: Neutralizing antibodies; bnAbs:
Broadly neutralizing antibodies; MLV: Modified live virus; ORF: Open reading frame; CON: Consensus sequence; GP: Glycoprotein; VDJ: Variable diversity joining; CDR: Complementary-determining region; NADC: National animal disease center; DMEM: Dulbecco's minimum essential median; FBS: Fetal bovine serum; PAMs: Pulmonary alveolar macrophages; CPE: Cytopathic effect; BHK-21: Baby hamster kidney 21; Marc-145: An African green monkey kidney cell line; hpi: Hours post-infection; hpt: Hours post-transfection; dpi: Days post-infection; dpc: Days post-challenge; IFA: Indirect immunofluorescence assay; $\mathrm{TCID}_{50}$ : Median tissue culture infectious doses; MOl: Multiplicity of infection; PBMCs: Periphery blood mononuclear cells; IFN: Interferon; ELISA: Enzyme-linked immunosorbent assay; RPMI: Roswell Park Memorial Institute; HDV: Hepatitis D virus; SD: Standard deviations.

\section{Supplementary Information}

The online version contains supplementary material available at https://doi. org/10.1186/s13567-021-00944-8.

Additional file 1. Alignment of 271 porcine VDJ amino acid sequences from this study. Overall, the variation of swine VDJ genes is concentrated in the CDR (A). The detailed alignment of 271 VDJ (B). The identical sequences from each pig are highlighted in red.

\section{Acknowledgements}

The authors would like to acknowledge Dr Xizhao Chen from Beijing Anheal Laboratories Co. Ltd. for providing the NADC34-like PRRSV2 Anheal-1 isolate.

\section{Authors' contributions}

$N C, S L, X L, J L$ and $M Q$ performed the experiments and analyzed the data; $Y T$, SL and SS performed the Flow cytometric analyses; $Z S$ and $X Y$ performed the histopathological and immunohistochemical examinations; NC, SL, XL, JL, MQ, $Y X$ and $X Y$ helped with the animal experiments; NC, HL, KT, SS and JZ drafted the manuscript. NC, SS and JZ co-supervised the experimental design and implementation. All authors read and approved the final manuscript.

\section{Funding}

This work was supported by National Natural Science Foundation of China (31802172), Natural Science Foundation of Jiangsu Province (BK20170492), and the Priority Academic Program Development of Jiangsu Higher Education Institutions (PAPD). Dr Chen is supported by High Talent Supporting Program of Yangzhou University.

\section{Availability of data and materials}

All the data generated or analyzed during the study are included in this article. The datasets used in the present research project are available from the corresponding authors upon reasonable request.

\section{Declarations}

Ethics approval and consent to participate

All animal experiments in this study were approved by the Animal Welfare and Ethics Committee of Yangzhou University with the Reference number of 202010001.

\section{Competing interests}

The authors declare that they have no competing interests.

\section{Author details}

${ }^{1}$ College of Veterinary Medicine, Yangzhou University, Yangzhou 225009, Jiangsu, China. ${ }^{2}$ Joint International Research Laboratory of Agriculture and Agri-Product Safety, Yangzhou 225009, Jiangsu, China. ${ }^{3}$ Comparative Medicine Research Institute, Yangzhou University, Yangzhou 225009, Jiangsu, China. ${ }^{4}$ Jiangsu Co-Innovation Center for Prevention and Control of Important Animal Infectious Diseases and Zoonoses, Yangzhou 225009, China. ${ }^{5}$ National Research Center for Veterinary Medicine, Luoyang 471003, Henan, China.

Received: 12 January 2021 Accepted: 3 April 2021

Published online: 27 May 2021 


\section{References}

1. Lunney JK, Fang Y, Ladinig A, Chen N, Li Y, Rowland B, Renukaradhya GJ (2016) Porcine reproductive and respiratory syndrome virus (PRRSV): pathogenesis and interaction with the immune system. Ann Rev Anim Biosci 4:129-154

2. Normile D (2007) Virology. China, Vietnam grapple with "rapidly evolving" pig virus. Science 317:1017

3. Walker PJ, Siddell SG, Lefkowitz EJ, Mushegian AR, Adriaenssens EM, Dempsey DM, Dutilh BE, Harrach B, Harrison RL, Hendrickson RC, Junglen S, Knowles NJ, Kropinski AM, Krupovic M, Kuhn JH, Nibert M, Orton RJ, Rubino L, Sabanadzovic S, Simmonds P, Smith DB, Varsani A, Zerbini FM, Davison AJ (2020) Changes to virus taxonomy and the Statutes ratified by the International Committee on Taxonomy of Viruses (2020). Arch Virol 165:2737-2748

4. Shi M, Lam TT, Hon CC, Hui RK, Faaberg KS, Wennblom T, Murtaugh MP, StadejekT, Leung FC (2010) Molecular epidemiology of PRRSV: a phylogenetic perspective. Virus Res 154:7-17

5. Chen NH, Xiao YZ, Ye MX, Li XS, Li SB, Xie NJ, Wei Y, Wang JL, Zhu JZ (2020) High genetic diversity of Chinese porcine reproductive and respiratory syndrome viruses from 2016 to 2019. Res Vet Sci 131:38-42

6. Guo B, Chen Z, Liu W, Cui Y (1996) Isolation and identification of porcine reproductory and respiratory syndrome (PRRS) virus from aborted fetuses suspected of PRRS. Chin J Prev Vet Med 2:1-5

7. Tian K, Yu X, Zhao T, Feng Y, Cao Z, Wang C, Hu Y, Chen X, Hu D, Tian X, Liu D, Zhang S, Deng X, Ding Y, Yang L, Zhang Y, Xiao H, Qiao M, Wang B, Hou L, Wang X, Yang X, Kang L, Sun M, Jin P, Wang S, Kitamura Y, Yan J, Gao GF (2007) Emergence of fatal PRRSV variants: unparalleled outbreaks of atypical PRRS in China and molecular dissection of the unique hallmark. PLoS One 2:e526

8. Zhao K, Ye C, Chang XB, Jiang CG, Wang SJ, Cai XH, Tong GZ, Tian ZJ, Shi M, An TQ (2015) Importation and recombination are responsible for the latest emergence of highly pathogenic porcine reproductive and respiratory syndrome virus in China. J Virol 89:10712-10716

9. Zhang HL, Zhang WL, Xiang LR, Leng CL, Tian ZJ, Tang YD, Cai XH (2018) Emergence of novel porcine reproductive and respiratory syndrome viruses (ORF5 RFLP 1-7-4 viruses) in China. Vet Microbiol 222:105-108

10. Goldberg TL, Lowe JF, Milburn SM, Firkins LD (2003) Quasispecies variation of porcine reproductive and respiratory syndrome virus during natural infection. Virology 317:197-207

11. Vu HLX, Ma FR, Laegreid WW, Pattnaik AK, Steffen D, Doster AR, Osorio FA (2015) A synthetic porcine reproductive and respiratory syndrome virus strain confers unprecedented levels of heterologous protection. J Virol 89:12070-12083

12. Robinson SR, Li J, Nelson EA, Murtaugh MP (2015) Broadly neutralizing antibodies against the rapidly evolving porcine reproductive and respiratory syndrome virus. Virus Res 203:56-65

13. Trible BR, Popescu LN, Monday N, Calvert JG, Rowland RRR (2015) A single amino acid deletion in the matrix protein of porcine reproductive and respiratory syndrome virus confers resistance to a polyclonal swine antibody with broadly neutralizing activity. J Virol 89:6515-6520

14. Ostrowski M, Galeota JA, Jar AM, Platt KB, Osorio FA, Lopez OJ (2002) Identification of neutralizing and nonneutralizing epitopes in the porcine reproductive and respiratory syndrome virus GP5 ectodomain. J Virol 76:4241-4250

15. Vanhee M, Van Breedam W, Costers S, Geldhof M, Noppe Y, Nauwynck H (2011) Characterization of antigenic regions in the porcine reproductive and respiratory syndrome virus by the use of peptide-specific serum antibodies. Vaccine 29:4794-4804

16. Chen N, Trible BR, Rowland RRR (2017) Amplification and selection of PRRSV-activated VDJ repertoires in pigs secreting distinct neutralizing antiboidies. Vet Immunol Immunopathol 189:53-57

17. Popescu LN, Trible BR, Chen NH, Rowland RRR (2017) GP5 of porcine reproductive and respiratory syndrome virus (PRRSV) as a target for homologous and broadly neutralizing antibodies. Vet Microbiol 209:90-96

18. Biswas M, Yamazaki T, Chiba J, Akashi-Takamura S (2020) Broadly neutralizing antibodies for influenza: passive immunotherapy and intranasal vaccination. Vaccines 8:424

19. del Moral-Sanchez I, Sliepen K (2019) Strategies for inducing effective neutralizing antibody responses against HIV-1. Expert Rev Vaccines 18:1127-1143
20. Ni YY, Opriessnig T, Zhou L, Cao DJ, Huang YW, Halbur PG, Meng XJ (2013) Attenuation of porcine reproductive and respiratory syndrome virus by molecular breeding of virus envelope genes from genetically divergent strains. J Virol 87:304-313

21. Zhou L, Ni YY, Pineyro P, Cossaboom CM, Subramaniam S, Sanford BJ Dryman BA, Huang YW, Meng XJ (2013) Broadening the heterologous cross-neutralizing antibody inducing ability of porcine reproductive and respiratory syndrome virus by breeding the GP4 or M genes. PLoS One 8:e66645

22. Zhou L, Ni YY, Pineyro P, Sanford BJ, Cossaboom CM, Dryman BA, Huang YW, Cao DJ, Meng XJ (2012) DNA shuffling of the GP3 genes of porcine reproductive and respiratory syndrome virus (PRRSV) produces a chimeric virus with an improved cross-neutralizing ability against a heterologous PRRSV strain. Virology 434:96-109

23. Tian DB, Ni YY, Zhou L, Opriessnig T, Cao DJ, Pineyro P, Yugo DM, Overend C, Cao Q, Heffron CL, Halbur PG, Pearce DS, Calvert JG, Meng XJ (2015) Chimeric porcine reproductive and respiratory syndrome virus containing shuffled multiple envelope genes confers cross-protection in pigs. Virology 485:402-413

24. Chen N, Ye M, Huang Y, Li S, Xiao Y, Li X, Li S, Li X, Yu X, Tian K, Zhu J (2019) Identification of two porcine reproductive and respiratory syndrome virus variants sharing high genomic homology but with distinct virulence. Viruses 11:875

25. Chen NH, Li SB, Li XS, Ye MX, Xiao YZ, Yan XL, Li XD, Zhu JZ (2020) The infectious CDNA clone of commercial HP-PRRS JXA1-R-attenuated vaccine can be a potential effective live vaccine vector. Transbound Emerg Dis 67:1820-1827

26. Chen N, Liu Q, Qiao M, Deng X, Chen X, Sun M (2017) Whole genome characterization of a novel porcine reproductive and respiratory syndrome virus 1 isolate: genetic evidence for recombination between Amervac vaccine and circulating strains in mainland China. Infect Genet Evol 54:308-313

27. Chen N, Li X, Xiao Y, Li S, Zhu J (2021) Characterization of four types of MLV-derived porcine reproductive and respiratory syndrome viruses isolated in unvaccinated pigs from 2016 to 2020. Res Vet Sci 134:102-111

28. Chen N, Li S, Ye M, Huang Y, Huang Y, Xiao Y, Yu X, Dong J, Tian K, Zhu J (2019) A novel NADC30-like porcine reproductive and respiratory syndrome virus (PRRSV) plays a limited role in the pathogenicity of porcine circoviruses (PCV2 and PCV3) and PRRSV co-infection. Transbound Emerg Dis 66:28-34

29. Chen N, Ye M, Li S, Huang Y, Zhou R, Yu X, Tian K, Zhu J (2018) Emergence of a novel highly pathogenic recombinant virus from three lineages of porcine reproductive and respiratory syndrome virus 2 in China 2017. Transbound Emerg Dis 65:1775-1785

30. Chen N, Cao Z, Yu X, Deng X, Zhao T, Wang L, Liu Q, Li X, Tian K (2011) Emergence of novel European genotype porcine reproductive and respiratory syndrome virus in mainland China. J Gen Virol 92:880-892

31. Larkin MA, Blackshields G, Brown NP, Chenna R, McGettigan PA, McWilliam H, Valentin F, Wallace IM, Wilm A, Lopez R, Thompson JD, Gibson TJ, Higgins DG (2007) Clustal W and Clustal X version 2.0. Bioinformatics 23:2947-2948

32. Chen N, Ye M, Xiao Y, Li S, Huang Y, Li X, Tian K, Zhu J (2019) Development of universal and quadruplex real-time RT-PCR assays for simultaneous detection and differentiation of porcine reproductive and respiratory syndrome viruses. Transbound Emerg Dis 66:2271-2278

33. Ansari IH, Kwon B, Osorio FA, Pattnaik AK (2006) Influence of N-linked glycosylation of porcine reproductive and respiratory syndrome virus GP5 on virus infectivity, antigenicity, and ability to induce neutralizing antibodies. J Virol 80:3994-4004

34. Cao QM, Tian D, Heffron CL, Subramaniam S, Opriessnig T, Foss DL, Calvert JG, Meng XJ (2019) Cytotoxic T lymphocyte epitopes identified from a contemporary strain of porcine reproductive and respiratory syndrome virus enhance CD4+CD8+ T, CD8 $+\mathrm{T}$, and gammadelta $T$ cell responses. Virology 538:35-44

35. Shang S, Siddiqui S, Bian Y, Zhao J, Wang CR (2016) Nonclassical MHC Ib-restricted CD8+T cells recognize Mycobacterium tuberculosis-derived protein antigens and contribute to protection against infection. PLoS Pathog 12:e1005688

36. Chen N, Trible BR, Kerrigan MA, Tian K, Rowland RR (2016) ORF5 of porcine reproductive and respiratory syndrome virus (PRRSV) is a target of 
diversifying selection as infection progresses from acute infection to virus rebound. Infect Genet Evol 40:167-175

37. Butler JE, Sun J, Wertz N, Sinkora M (2006) Antibody repertoire development in swine. Dev Comp Immunol 30:199-221

38. Vollmers C, Sit RV, Weinstein JA, Dekker CL, Quake SR (2013) Genetic measurement of memory B-cell recall using antibody repertoire sequencing. Proc Natl Acad Sci USA 110:13463-13468

39. Mengeling WL, Lager KM, Vorwald AC, Clouser DF (2003) Comparative safety and efficacy of attenuated single-strain and multi-strain vaccines for porcine reproductive and respiratory syndrome. Vet Microbiol 93:25-38

40. Shabir N, Khatun A, Nazki S, Kim B, Choi EJ, Sun D, Yoon KJ, Kim WI (2016) Evaluation of the cross-protective efficacy of a chimeric porcine reproductive and respiratory syndrome virus constructed based on two field strains. Viruses 8:240

41. Tian DB, Cao DJ, Heffron CL, Yugo DM, Rogers AJ, Overend C, Matzinger SR, Subramaniam S, Opriessnig T, LeRoith T, Meng XJ (2017) Enhancing heterologous protection in pigs vaccinated with chimeric porcine reproductive and respiratory syndrome virus containing the full-length sequences of shuffled structural genes of multiple heterologous strains. Vaccine 35:2427-2434

42. Shi M, Holmes EC, Brar MS, Leung FC (2013) Recombination is associated with an outbreak of novel highly pathogenic porcine reproductive and respiratory syndrome viruses in China. J Virol 87:10904-10907

43. Lu WH, Tun HM, Sun BL, Mo J, Zhou QF, Deng YX, Xie QM, Bi YZ, Leung FC, Ma JY (2015) Re-emerging of porcine respiratory and reproductive syndrome virus (lineage 3) and increased pathogenicity after genomic recombination with vaccine variant. Vet Microbiol 175:332-340

44. Zhou L, Wang Z, Ding Y, Ge X, Guo X, Yang H (2015) NADC30-like strain of porcine reproductive and respiratory syndrome virus, China. Emerg Infect Dis 21:2256-2257

45. Bai X, Wang Y, Xu X, Sun Z, Xiao Y, Ji G, Li Y, Tan F, Li X, Tian K (2016) Commercial vaccines provide limited protection to NADC30-like PRRSV infection. Vaccine 34:5540-5545

46. Zhou L, Yang B, Xu L, Jin H, Ge X, Guo X, Han J, Yang H (2017) Efficacy evaluation of three modified-live virus vaccines against a strain of porcine reproductive and respiratory syndrome virus NADC30-like. Vet Microbiol 207:108-116

47. Guo Z, Chen XX, Li R, Qiao S, Zhang G (2018) The prevalent status and genetic diversity of porcine reproductive and respiratory syndrome virus in China: a molecular epidemiological perspective. Virol J 15:2

48. Zhai SL, Lin T, Zhou X, Pei ZF, Wei ZZ, Zhang H, Wen XH, Chen QL, Lv DH, Wei WK (2018) Phylogeographic analysis of porcine reproductive and respiratory syndrome virus 1 in Guangdong province, Southern China. Arch Virol 163:2443-2449

49. Lopez OJ, Oliveira MF, Garcia EA, Kwon BJ, Doster A, Osorio FA (2007) Protection against porcine reproductive and respiratory syndrome virus (PRRSV) infection through passive transfer of PRRSV-neutralizing antibodies is dose dependent. Clin Vaccine Immunol 14:269-275

50. Osorio FA, Galeota JA, Nelson E, Brodersen B, Doster A, Wills R, Zuckermann F, Laegreid WW (2002) Passive transfer of virus-specific antibodies confers protection against reproductive failure induced by a virulent strain of porcine reproductive and respiratory syndrome virus and establishes sterilizing immunity. Virology 302:9-20

51. Wu CY, Gu GQ, Zhai TS, Wang YJ, Yang YL, Li YF, Zheng X, Zhao Q, Zhou EM, Nan YC (2020) Broad neutralization activity against both PRRSV-1 and PRRSV- 2 and enhancement of cell mediated immunity against PRRSV by a novel IgM monoclonal antibody. Antivir Res 175:104716

52. Market E, Papavasiliou FN (2003) V(D)J recombination and the evolution of the adaptive immune system. PLoS Biol 1:E16
53. Padlan EA (1977) Structural basis for the specificity of antibody-antigen reactions and structural mechanisms for the diversification of antigenbinding specificities. Q R Biophys 10:35-65

54. Butler JE, Wertz N (2012) The porcine antibody repertoire: variations on the textbook theme. Front Immunol 3:153

55. Butler JE, Lemke CD, Weber P, Sinkora M, Lager KM (2007) Antibody repertoire development in fetal and neonatal piglets: XIX. Undiversified B cells with hydrophobic HCDR3s preferentially proliferate in the porcine reproductive and respiratory syndrome. J Immunol 178:6320-6331

56. Lemke CD, Haynes JS, Spaete R, Adolphson D, Vorwald A, Lager K, Butler JE (2004) Lymphoid hyperplasia resulting in immune dysregulation is caused by porcine reproductive and respiratory syndrome virus infection in neonatal pigs. J Immunol 172:1916-1925

57. Sinkora M, Sinkorova J (2014) B cell lymphogenesis in swine is located in the bone marrow. J Immunol 193:5023-5032

58. Murtaugh MP, Genzow M (2011) Immunological solutions for treatment and prevention of porcine reproductive and respiratory syndrome (PRRS). Vaccine 29:8192-8204

59. Zuckermann FA, Garcia EA, Luque ID, Christopher-Hennings J, Doster A, Brito M, Osorio F (2007) Assessment of the efficacy of commercial porcine reproductive and respiratory syndrome virus (PRRSV) vaccines based on measurement of serologic response, frequency of gamma-IFN-producing cells and virological parameters of protection upon challenge. Vet Microbiol 123:69-85

60. Meier WA, Husmann RJ, Schnitzlein WM, Osorio FA, Lunney JK, Zuckermann FA (2004) Cytokines and synthetic double-stranded RNA augment the Thelper 1 immune response of swine to porcine reproductive and respiratory syndrome virus. Vet Immunol Immunopathol 102:299-314

61. Charerntantanakul W (2012) Porcine reproductive and respiratory syndrome virus vaccines: immunogenicity, efficacy and safety aspects. World J Virol 1:23-30

62. Li B, Fang L, Xu Z, Liu S, Gao J, Jiang Y, Chen H, Xiao S (2009) Recombination in vaccine and circulating strains of porcine reproductive and respiratory syndrome viruses. Emerg Infect Dis 15:2032-2035

63. Jiang YF, Xia TQ, Zhou YJ, Yu LX, Yang S, Huang QF, Li LW, Gao F, Qu ZH, Tong W, Tong GZ (2015) Characterization of three porcine reproductive and respiratory syndrome virus isolates from a single swine farm bearing strong homology to a vaccine strain. Vet Microbiol 179:242-249

64. Yu LX, Wang X, Yu H, Jiang YF, Gao F, Tong W, Li LW, Li HC, Yang S, Chen PF, Yang DQ, Zhang WC, Tong GZ, Zhou YJ (2018) The emergence of a highly pathogenic porcine reproductive and respiratory syndrome virus with additional 120aa deletion in Nsp2 region in Jiangxi, China. Transbound Emerg Dis 65:1740-1748

\section{Publisher's Note}

Springer Nature remains neutral with regard to jurisdictional claims in published maps and institutional affiliations.

Ready to submit your research? Choose BMC and benefit from:

- fast, convenient online submission

- thorough peer review by experienced researchers in your field

- rapid publication on acceptance

- support for research data, including large and complex data types

- gold Open Access which fosters wider collaboration and increased citations

- maximum visibility for your research: over 100M website views per year

At BMC, research is always in progress.

Learn more biomedcentral.com/submissions 